\title{
Effect of blisters and rims on radial hydride precipitation in fuel elements under dry storage conditions
}

\author{
María Inés Luppo ${ }^{1}$, Francisco Roberto Amoruso ${ }^{2}$,
} Roberto Haddad ${ }^{1}$, Gladys Domizzi ${ }^{1,3}$

\author{
${ }^{1}$ Materials Department, Argentina Atomic Energy Commission, Av. Gral Paz 1499, (B1650KNA) San Martín, Buenos \\ Aires, Argentina \\ e-mail: luppo@cnea.gov.ar, haddad@cnea.gov.ar,domizzi@cnea.gov.ar \\ ${ }^{2}$ Nuclear Fuel Department, Argentina Atomic Energy Commission, Av. Gral Paz 1499, (B1650KNA) San Martín, Bue- \\ nos Aires, Argentina \\ e-mail: amoruso@cnea.gov.ar \\ ${ }^{3}$ Instituto Sabato, National University of San Martín - Argentina Atomic Energy Commission, Av. Gral Paz 1499, \\ (B1650KNA) San Martín, Buenos Aires, Argentina.
}

\begin{abstract}
Hydrogen enters in Zry clads during fuel element life in service; when hydrogen exceeds the terminal solid solubility, circumferential hydrides are precipitated. In the presence of thermal gradients, produced for instance by oxide spallation, localized concentration of hydrides - known as blisters - can be formed. Due to the fact that zirconium hydrides have a lower density that zirconium alloys, stresses are produced around blisters. These stresses may overcome the necessary threshold to precipitate radial hydrides. Moreover, cracks inside blisters may act as initiators of delayed hydride cracking (DHC).

In the dry storage facilities developed for Atucha 1, Zry - 4 clads of spent fuel elements (SFE) must withstand environmental conditions which include maximum temperature of $200^{\circ} \mathrm{C}$ and internal SFE pressure of $\sim 75$ bar (value at end of cycle). During dry storage, if blisters are present, stresses around them are superposed to circumferential stresses generated by the internal pressure due to fission gasses helping precipitation and/or growth of radial hydrides and DHC process. In order to assess this possibility, in the present work sections of Zry-4 cladding were hydrided. Blisters have been grown by thermal gradient under different conditions of temperature and shapes of thermal contact in order to obtain different blister dimensions and fraction of radial hydrides. After blister formation, some specimens were subjected to Hydride Reorientation Test (HRT) by applying an internal pressure of 75 bar at $200^{\circ} \mathrm{C}$. Finally, tubes were sectioned and metallographically analyzed looking for radial hydrides.
\end{abstract}

In some samples radial hydrides were observed, which effectively grew by the internal pressure of Zrycladding during HRT.

Keywords: zirconium hydrides, dry storage, Zry-4, blister, hydride reorientation.

\section{INTRODUCTION}

Dry storage is currently being considered as a method of managing commercial nuclear fuels before delayed reprocessing or final disposal. Creep has come to be regarded as a dominant mechanism of cladding deformation. However, hydride reorientation (HR) and/or delayed hydride cracking (DHC), and blisters and rims formation are mechanisms of failure feasible to occur in spent fuel cladding (SFC) during dry storage. The HR phenomenon usually involves the dissolution of circumferential hydrides and the formation of zirconium hydrides oriented perpendicular to the hoop, hereby referred as radial hydrides [1].

Hoop stresses are mainly produced by internal pressure of gasses released during fuel cladding operation. In fuel claddings of Atucha 1, the maximum (conservative) end of life pressure at $360^{\circ} \mathrm{C}$ is 100 bar. At $200^{\circ} \mathrm{C}$, the maximum nominal temperature during dry storage, this pressure drops to 75 bar and it would produce a hoop stress of $81 \mathrm{MPa}$.

The following analysis tries to evaluate the possibility of the HR process and the failure occurrence risk. 


\subsection{Hydride embrittlement (HE)}

Whenever hydrogen concentration in Zircaloy exceeds the terminal solid solubility for precipitation (TSSP), hydrides may precipitate. This is indeed the case for Atucha 1 spent fuel elements, where at end-of-life hydrogen picks up may range between 100 and $200 \mathrm{ppm}$. Provided no temperature or stress gradients are present at operating conditions $\left(400^{\circ} \mathrm{C}\right)$ a hydrogen concentration in excess of $336 \mathrm{ppm}$ is necessary for hydride precipitation (according to Mc Minn's terminal solid solubility for precipitation curve (TSSP) in irradiated Zry); however, during wet storage period, complete precipitation will occur (at $20^{\circ} \mathrm{C}$ saturation is reached with only $6.9 \mathrm{ppm}$ in irradiated material). According to Mc Minn's terminal solid solubility for dissolution curve (TSSD) [2], at the design maximum temperature during drying procedure $\left(\sim 200^{\circ} \mathrm{C}\right)$ the TSSD at $200^{\circ} \mathrm{C}$ is $19 \mathrm{ppm}$ if temperature is reached by heating, so an important fraction will stay precipitated ( $~ 81 \mathrm{ppm}$ if the hydrogen content incorporated during service is $100 \mathrm{ppm})$.

Hydrogen concentration could be higher if ingress of water into fuel element has happened due to any type of failure. Even the deterioration or removal of the cladding external oxide is enough to produce an increase. In the absence of stresses, hydrides normally precipitate on the circumferential-axial plane, producing no ductility reduction with hydrogen content below 700-800 ppm [3-7], well above the available amount. However, when radial hydrides are present, this critical concentration is significantly reduced, 55 ppm according to MARSHALL and LOUTHAN [8].

Recently, numerous studies have been carried out in order to calculate the minimum necessary stress to produce precipitation of radial hydrides during cooling which takes place during dry storage. In relation to this "reorientation" process (from circumferential to radial position) the first point to be considered is the maximum temperature to which the cladding has been subjected; because this determines the hydrogen concentration in solution (TSSP or TSSD, depending on the thermal history) from which precipitation of radial hydrides will occur. Consequently, the amount of precipitated radial hydrides is independent of the total cladding hydrogen concentration. Secondly, the hoop stress (generated by internal pressure of fission gases) should be higher than the threshold for radial hydride formation. Irradiated materials seem to have lower threshold stress than unirradiated. VALANCE, et al. [9] reported $50 \mathrm{MPa}$ for irradiated Zry-2 and 65$74 \mathrm{MPa}$ for the same unirradiated material. Values above $100 \mathrm{MPa}$ have been reported in Zry-4 [10] and less than $70 \mathrm{MPa}$ in Zry-2 cladding of SFE [10]. Finally, the radial hydrides fraction increases inversely with cooling speed.

A hoop stress of around $81 \mathrm{MPa}$ in Zry-4 is near but insufficient to produce precipitation of radial hydrides, even with very low cooling speeds. This, together with the scarce supply of hydrogen in solution ( $19 \mathrm{ppm}$ ), would indicate that embrittlement would not take place. Nevertheless, this assumption must be corroborated with proper studies in Atucha 1 irradiated cladding.

\subsection{Blisters and rims}

Hydride precipitates often form preferentially near the outer (cooler) surface of cladding. Eventually, a continuous layer (rim) or lens (blisters) containing high concentration of hydrides can also form under thermal gradient produced by oxide spallation or under a stress gradient. GLENDENING, et al. [11], ELLS [12] studied the fracture behaviour of unirradiated Zry-4 sheet containing brittle hydride rims or blisters. They found that failure strain under equal-biaxial or plane strain tensile deformation decreases with increasing hydride blisters or rim thickness, especially in the $<100 \mu \mathrm{m}$ range.

HERMANN, et al. [13] performed high-temperature low-strain rate burst tests on irradiated cladding samples with and without blisters. They have shown that large hydride lens and rim initiate specimen rupture during burst test at $350^{\circ} \mathrm{C}$ (burst pressure $=262-453 \mathrm{bar}$ ), but small hydride lens $\left(1-3 \mathrm{~mm}^{2}\right.$ ) did not contribute to burst opening. Nevertheless, these small lenses may present cracks inside as were observed in blisters with area lower than $1 \mathrm{~mm}^{2}$, grown in laboratory in $\mathrm{Zr}-2.5 \mathrm{Nb}$ [6-7], which are potential stress concentrators, promoting DHC during storage.

Another fact to be taken into account is the stress field produced around a blister. Zirconium hydrides have lower density that zirconium alloys; consequently, during hydride precipitation there is an increase in volume. The stresses produced by the misfit strain are high enough to overcome the threshold stress necessary to precipitate radial hydrides in the matrix. DOMIZZI, et al. [6-7] analysed different condition of blisters growth in $\mathrm{Zr}-2.5 \mathrm{Nb}$ which presented different hydride distribution around. During cooling, many hydride platelets are precipitated radially to the blister, even in the absence of external stresses. The precipitation of hydrides radially to the blister is favoured by a slower cooling rate, consistent with a process controlled by hydrogen diffusion. The size of the zone where these hydrides are precipitated increases as the temperature of the blister growth decreases. An increase in the matrix yield stress and the subsequent 
increase in the stresses developed around the blister can explain this fact. When external stresses are applied in the circumferential direction the blister acts as a stress concentrator. The stress gradient generated around the blister causes hydrogen diffusion (even if no thermal gradient is applied) and the radial hydrides grow in both length and thickness. If a crack originated in a blister crosses the blister/matrix boundary, it could propagate inside the matrix along the radial hydrides.

\subsection{Final considerations and work objectives}

From previous studies, several issues arise:

1. The stress conditions to produce reorientation of hydride are not fulfilled if only the hoop stress or the SFE weight is acting during storage of Atucha Zry-4 claddings.

2. Blisters can be formed during cladding life in service.

3. Blisters formed in service not always cause a perforation of tubes. It depends on the time elapsed from blister start forming until total penetration.

4. Assuming a blister that has not fully cracked the cladding but having radial hydrides around, it is likely that these radial hydrides can continue to grow until perforation of the tube during dry storage

5. An additional stress could be acting if blister were present in the cladding, which added to hoop stress could overpass threshold stress for radial hydride precipitation

The aim of this work was to evaluate if the stresses around blisters, added to the hoop stress, may be high enough to produce hydride reorientation under dry storage conditions $\left(200^{\circ} \mathrm{C}\right.$ and a hoop stress of 81 $\mathrm{MPa})$.

\section{MATERIALS AND METHODS}

Experiments were performed in sections of Zry-4 (1.2-1.7 ppm Sn; 0.18-0.24 ppm Fe; 0.07-0.13 ppm Cr and 1,400 ppm max O), material used in Atucha 1 nuclear plant as fuel claddings. The diameter and wall thickness of the tubes were $11.9 \mathrm{~mm}$ and $0.55 \mathrm{~mm}$, respectively. Specimens of $150 \mathrm{~mm}$ long were sectioned by means of diamond wheel.

Specimens were gaseous charged with hydrogen in a Sieverts device, which consists of a chamber (a quartz tube connected to a high vacuum system consisting of rotary and a turbo molecular pumps) and a hydrogen gas injection system (99.999\% purity). Prior hydrogen charging, the specimens were abraded with $\mathrm{SiC}$ paper of 600 mesh and cleaned with trichloroethylene. The maximum temperature during charging was $380^{\circ} \mathrm{C}$ to $450^{\circ} \mathrm{C}$. The hydrogen concentration was $100-150 \mathrm{ppm}$ in weight. A heat treatment at $370^{\circ} \mathrm{C}$ during $24 \mathrm{~h}$ was carried out in order to obtain uniform hydride distribution throughout the thickness.

Blisters were grown on each sample by applying a localized thermal gradient; thus producing a cold spot to which the hydrogen migrates until the concentration is high enough to produce a massive hydride precipitation. The experimental device was similar to that described in a previous work [6] (Figure 1). The sample was placed over an aluminum squared block heated in an electrical furnace. A copper rod was introduced inside the tube and the thermal gradient was obtained by pressing an aluminum cold finger (water refrigerated) on the upper surface of the sample. The contact area was a circle of $0.8 \mathrm{~mm}$ in diameter or a concave area with the curvature of the cladding of $5.5 \mathrm{~mm}$ in diameter. In some tests, to improve thermal conductivity, copper adhesive (ultra copper) was deposited between the sample and the cold finger. In others, aluminum, alumina or refractory powders were deposited. The temperature of the sample was measured with a J-type thermocouple spot welded on the sample surface at $30 \mathrm{~mm}$ from the cold finger. The temperature of the cold finger was measured at $11 \mathrm{~mm}$ from the sample surface with a thermocouple introduced in a hole. A thermal gradient was applied during different periods of time in order to obtain different blister dimensions. The temperature of the sample was in the range $270-430^{\circ} \mathrm{C}$ and the temperature of the cold finger was 30 $60^{\circ} \mathrm{C}$. 


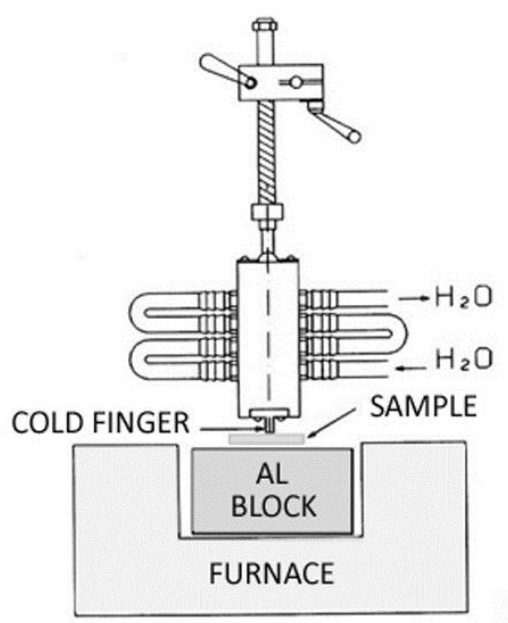

Figure 1: Experimental device for blisters formation [6].

After blister formation, some specimens were submitted to thermal treatment under inner pressure of Ar gas (HRT) to verify if radial hydride precipitation and/or delayed hydride cracking may occur. The specimen was introduced in a furnace; the pressure and temperature were held constant during 7 days to a month. After that, the specimen was furnace cooled. The temperature was $185^{\circ} \mathrm{C}-200^{\circ} \mathrm{C}$ and the pressure was 75 bar to simulate conservative conditions during Atucha 1 fuel dry storage.

Table 1 summarizes the conditions of test performed on each specimen.

Tabla 1: Summary of the conditions of tests performed on each specimen.

\begin{tabular}{|c|c|c|c|c|c|}
\hline \multirow[t]{2}{*}{ SPECIMEN } & \multirow{2}{*}{$\begin{array}{l}\text { HYDROGEN } \\
\text { CONCENTRA- } \\
\text { TION (ppm) }\end{array}$} & \multicolumn{3}{|c|}{ BLISTER GROWTH CONDITION } & \multirow{2}{*}{$\begin{array}{l}\text { HRT (TIME (DAYS)/ } \\
\text { TEMPERATURE }\left({ }^{\circ} \mathrm{C}\right)\end{array}$} \\
\hline & & $\begin{array}{l}\text { DIAMETER } \\
\text { OF COLD } \\
\text { FINGER }(\mathrm{mm})\end{array}$ & $\begin{array}{l}\text { MATERIAL } \\
\text { INTERPOSED }\end{array}$ & $\begin{array}{l}\text { TIME (DAYS)/ } \\
\text { TEMPERATURE } \\
\left({ }^{\circ} \mathrm{C}\right)\end{array}$ & \\
\hline SP/HRT & 128 (SPots) & \multicolumn{3}{|c|}{ Without blister formation treatment } & $7 / 185$ \\
\hline RI/HRT & $\begin{array}{l}108 \text { (RIing of } \\
\text { Pd film) }\end{array}$ & \multicolumn{3}{|c|}{ Without blister formation treatment } & $12 / 187$ \\
\hline 5.5-Al - a & $100-150$ & \multirow{2}{*}{$\begin{array}{c}5.5 \text { concave } \\
\text { contact }\end{array}$} & \multirow{2}{*}{$\begin{array}{l}\text { Aluminum } \\
\text { powders }\end{array}$} & $14 / 420$ & - \\
\hline 5.5-Al- b & $100-150$ & & & $15 / 420$ & - \\
\hline $0.8-\mathrm{Cu}-\mathrm{a} / \mathrm{HRT}$ & 120 & 0.8 & Cu adhesive & $14 / 334$ & $7 / 200$ \\
\hline $0.8-\mathrm{Cu}-\mathrm{b}$ & 123 & 0.8 & Cu adhesive & $6 / 327$ & - \\
\hline $0.8-\mathrm{Cu}-\mathrm{c} / \mathrm{HRT}$ & 120 & 0.8 & $\mathbf{C u}$ adhesive & $5 / 348$ & $6 / 205+0.8 / 250$ \\
\hline $0.8-\mathrm{A}$ & 120 & 0.8 & Alumina powders & $7 / 345$ & - \\
\hline $5.5-\mathrm{R}$ & 108 & \multirow{2}{*}{$\begin{array}{l}5.5 \text { concave } \\
\text { contact }\end{array}$} & \multirow{2}{*}{$\begin{array}{l}\text { Refractory } \\
\text { powders }\end{array}$} & $4 / 360$ & - \\
\hline 5.5-R/HRT & 111 & & & $4.7 / 320$ & $30 / 200$ \\
\hline
\end{tabular}

In order to measure blister dimension and observe hydride distribution around it, specimens were sectioned (see Figure 2) and metallographically analyzed looking for the presence of radial hydrides. Tube sections were progressively ground with $\mathrm{SiC}$ paper on the radial - circumferential plane. They were etched in a solution of $45 \mathrm{ml} \mathrm{HNO}_{3}, 45 \mathrm{ml}$ lactic acid and $4 \mathrm{ml} \mathrm{HF}$ and observed by means of an optical microscope. In order to confirm the uniform hydride distribution throughout the thickness after hydrogen charging, both extremes of specimens were observed. Moreover, hydride distribution around blisters was observed in some specimens without HRT and in others after HRT. 


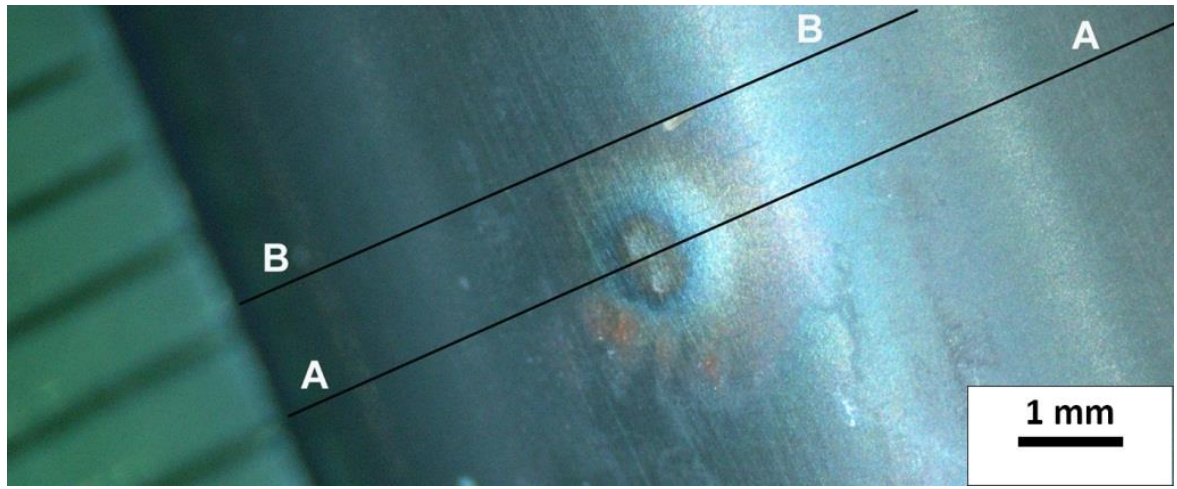

Figure 2: Blister in specimen 0.8-Cu-a/HRT with two positions of the blister sectioning, indicated with lines A-A and BB.

\section{RESULTS AND DISCUSSION}

All specimens (except samples SP/HRT and RI/HRT) showed uniform hydride distribution in transversal sections cut from the two ends of each specimen (Figure 3).

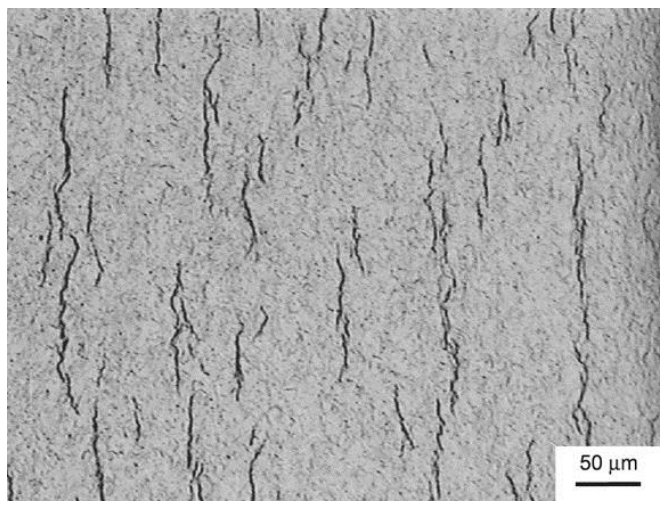

Figure 3: Hydride distribution in transversal section of specimen $0.8-\mathrm{Cu}-\mathrm{b}$.

On the external surface of specimen SP/HRT spots with high hydride concentration were produced during hydrogen charging, due to not uniform previous polishing (Figure 4.a). The transversal sectioning (Figure 4.b) shows that these spots are similar to hydride rims observed in SFC.

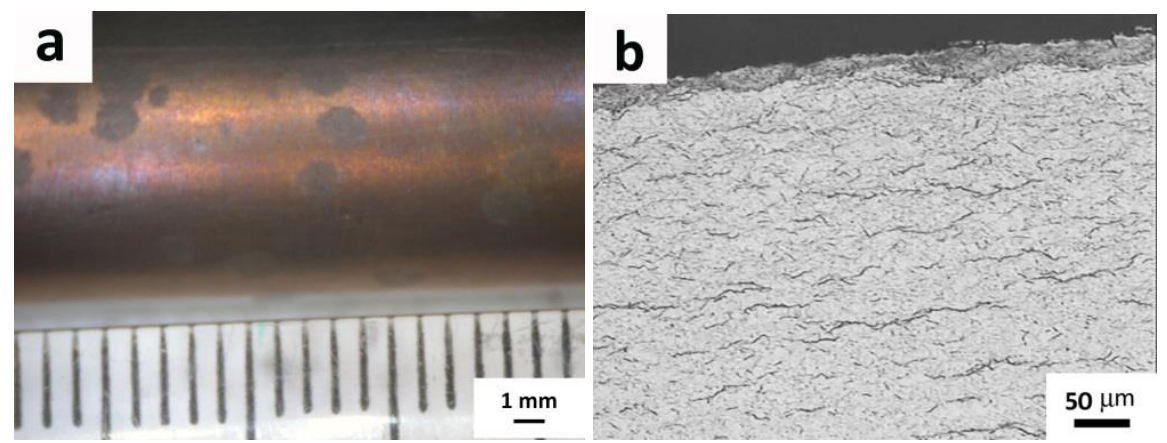

Figure 4: Sample SP/HRT a) Superficial view, b) Transversal section after HRT.

In sample RI/HRT a ring of palladium (1-2 $\mu \mathrm{m}$ in thickness) was electrodeposited, previous to hydrogen charging, in order to produce a hydride rim $(50 \mu \mathrm{m}$ depth) on the outer side of the tube as shown in Figure 5. Some cracks parallel to the tube surface have been formed in the hydride rim. In specimens SP/HRT and RI/HRT nor radial cracks neither radial hydrides were observed after the HRT. This fact demonstrates that the spots and rims are too shallow defects and that their presence does not produce circumferential stresses. 
The absence of radial hydrides is a demonstration that the hoop stress produced by inner pressure added to any other circumferential stress (if any) do not overpass the threshold to produce hydride reorientation; this is in agreement with the results obtained by Aomi et al [10].
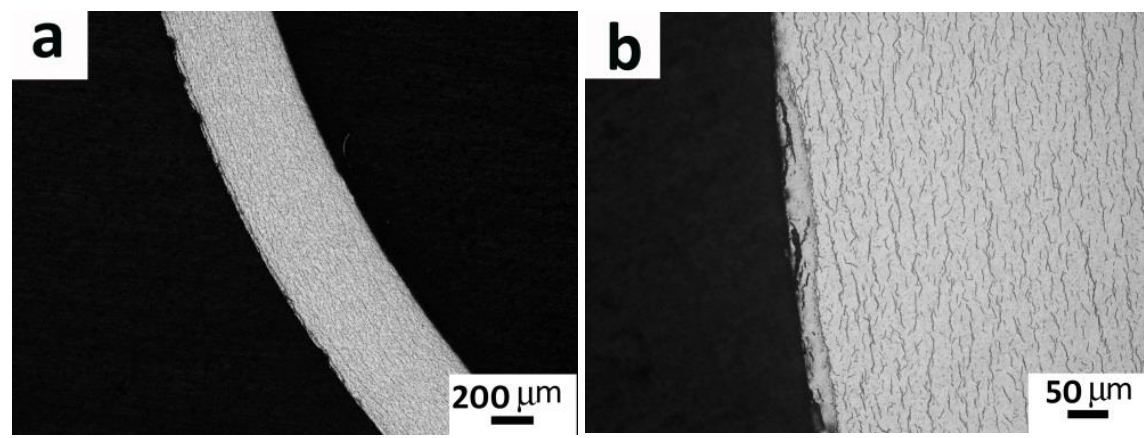

Figure 5: Sample RI/HRT. a) Hydride rim formed during hydrogen charge below the palladium ring; b) section of the rim with higher magnification, showing cracks parallel to the tube surface, both micrographs were taken after HRT.

Blisters in samples 5.5-Al-a and 5.5-Al-b were grown heating until $420^{\circ} \mathrm{C}$. In specimen 5.5-Al-a the temperature of cold finger was $70^{\circ} \mathrm{C}$ while in sample 5.5-Al-b was $50^{\circ} \mathrm{C}$ and a higher pressure was applied to assure a better contact between the cold finger and the upper surface of the sample. In sample 5.5-Al-a a circumferential spot was obtained which is more similar to a rim than to a blister; as was observed in specimens RI/HRT and S/HRT no radial hydrides were observed (Figure 6.a). In sample 5.5-Al-b, instead, a ring - shaped blister was formed which nearly cross the cladding wall (Figure 6.b). No radial hydrides were observed around the blisters, this fact can be attributed to the highest temperature during blister forming, which reduced the yield stress of Zry 4 and consequently the residual stress around the blister are not enough high to produce hydride reorientation as was observed by [6-7].
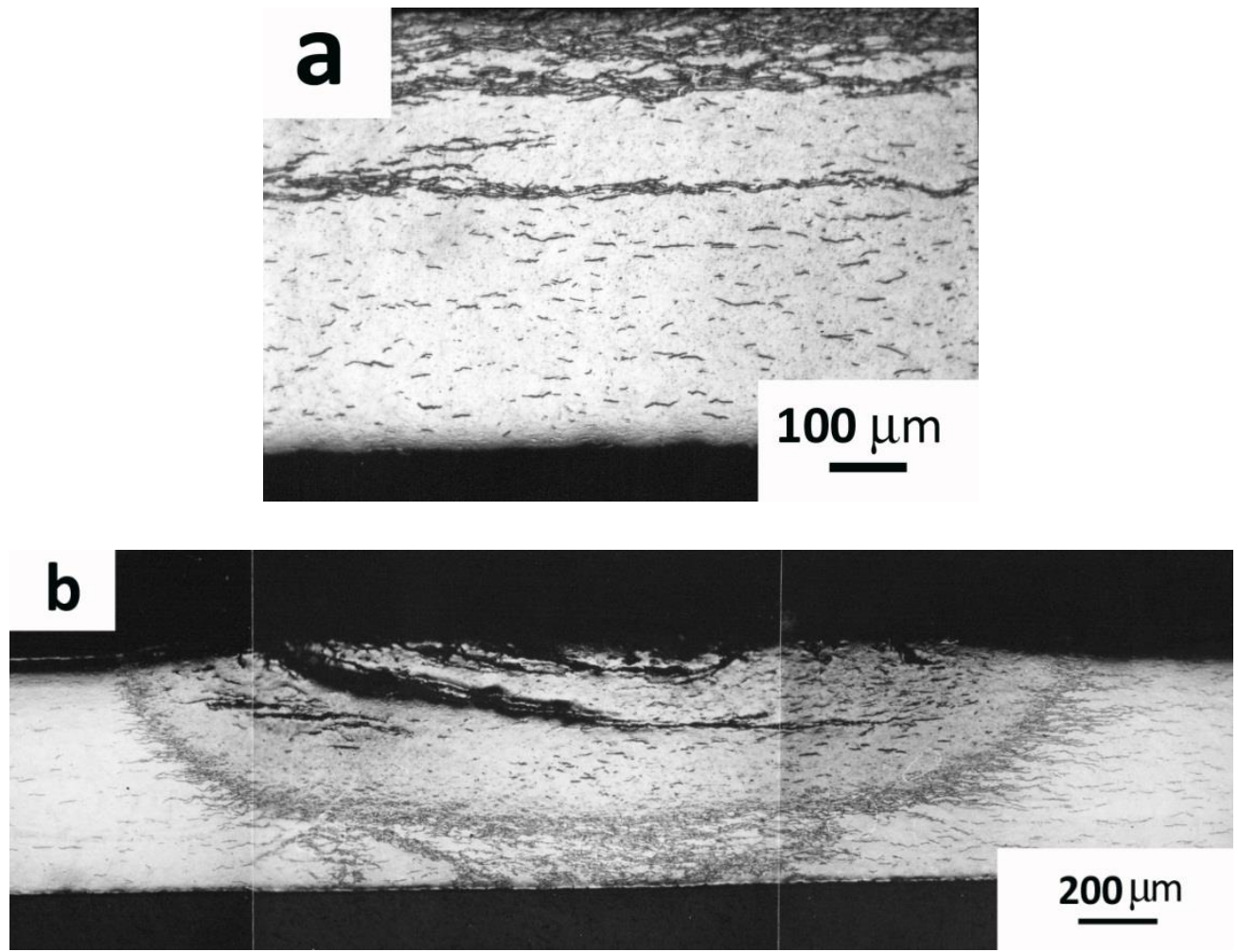

Figure 6: Section of the blister a) 5.5-Al-a and b) 5.5-Al-b.

In specimens $0.8-\mathrm{Cu}-\mathrm{a} / \mathrm{HRT}$, a contact finger of $0.8 \mathrm{~mm}$ in diameter was used to reduce the size of blisters. In order to improve thermal conductivity, a copper adhesive was deposited between samples and the 
cold finger. Optical micrograph of the blister in sample 0.8-Cu-a/HRT is shown in the Figure 7.a (near to section A-A of Figure 2). This blister nearly reaches the middle of the wall cladding and is surrounded by a very high density of circumferential hydrides. Section B-B is shown in Figure 8.a; circumferential hydrides density surrounding the blister is lower than in section A-A, and a higher density of radial hydrides can be seen. In specimens $0.8-\mathrm{Cu}-\mathrm{b}$ and $0.8-\mathrm{Cu}-\mathrm{c} / \mathrm{HRT}$ blisters were formed during shorter time ( 7 days) than in specimen 0.8-Cu-a/HRT, thus, blisters with lower depth were obtained (section A-A are shown in Figure 7.b and 7.c). Section B-B of specimen 0.8-Cu-b, without HRT (Figure 9.b) shows lower density of radial hydrides compared with specimens $0.8-\mathrm{Cu}-\mathrm{a} / \mathrm{HRT}$ and 0.8-Cu-c/HRT (Figure 9.a and 9.c, respectively) which would indicate that the HRT is effective in producing hydride reorientation. Another important fact is that cracks produced during blister growing can be seen on all specimens. Nevertheless, with the hoop stress applied during HRT, cracks inside blisters do not propagate into the Zry-4 matrix as was observed in [6-7]. This fact can be attributed to insufficient time during the HRT.
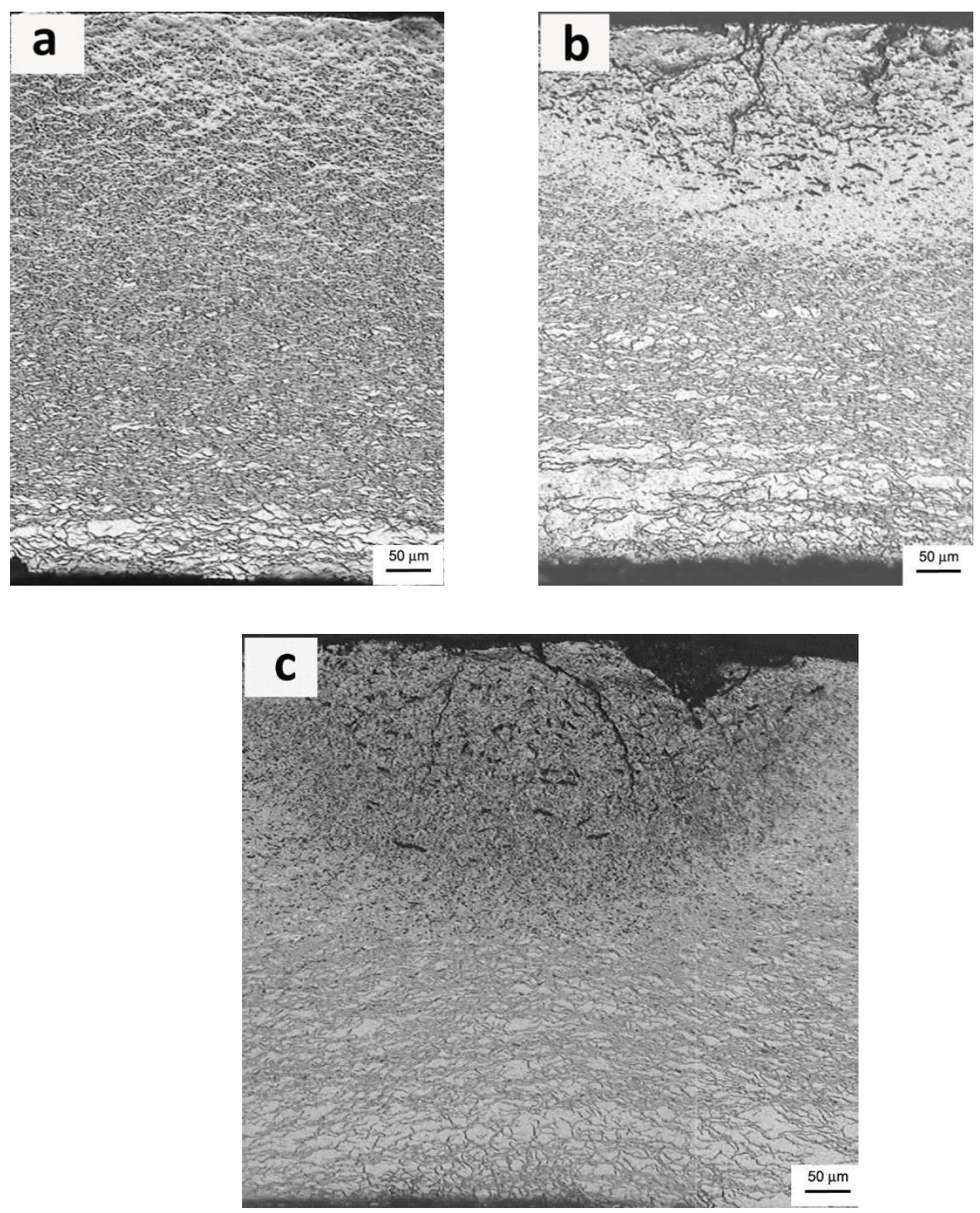

Figure 7: Blisters formed in: a) Near section A-A of 0.8-Cu-a/HRT; b) Section A-A of 0.8-Cu-b and c) Section A-A of $0.8-\mathrm{Cu}-\mathrm{c} / \mathrm{HRT}$. 

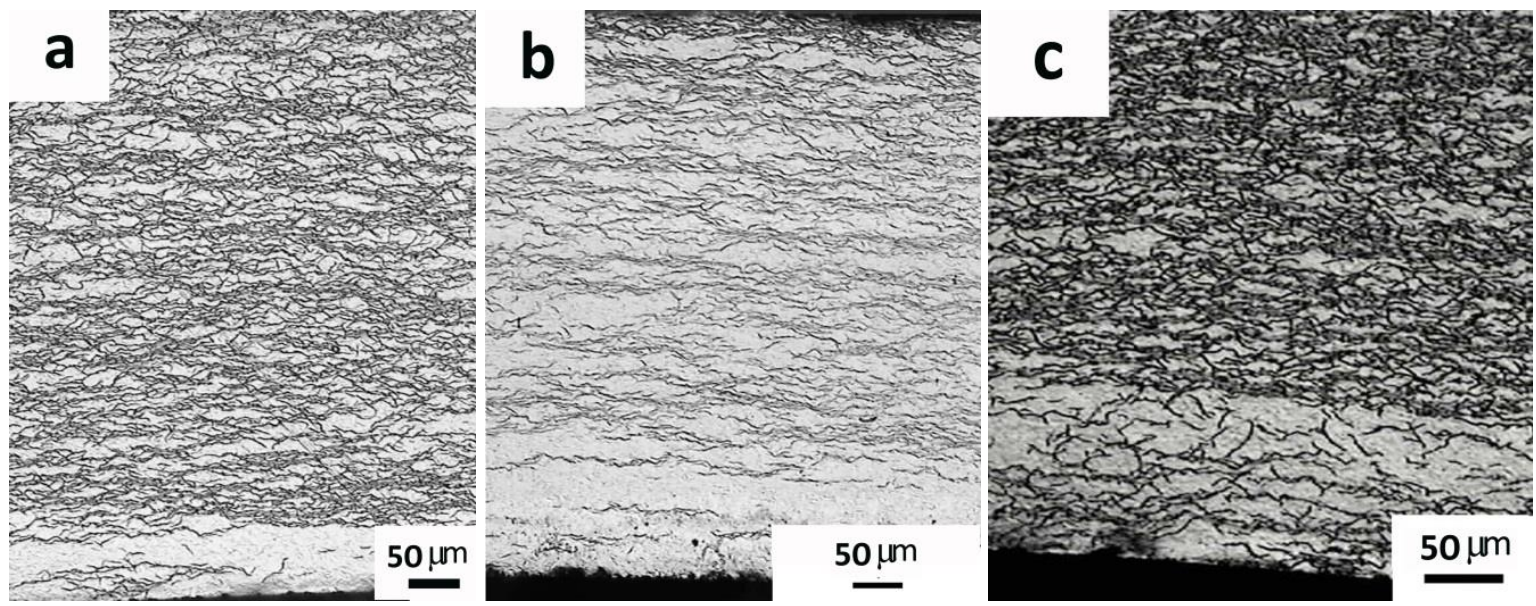

Figure 8: Section B-B of blisters shown in Figure 7. a) Specimen 0.8-Cu-a/HRT, b) specimen 0.8-Cu-b, c) specimen 0.8$\mathrm{Cu}-\mathrm{c} / \mathrm{HRT}$

In specimen 0.8-A the blister was grown interposing alumina powders between the specimen and cold finger with the intention of producing a lower thermal gradient and a smaller blister, but a dense blister which crosses the whole thickness of the specimen was obtained instead (Figure 9).

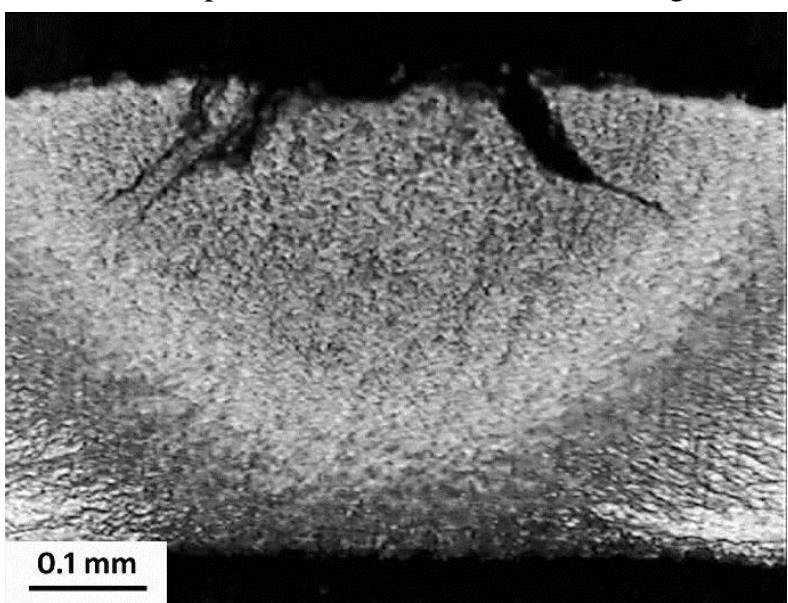

Figure 9: Section of the blister formed in specimen 0.8-A.
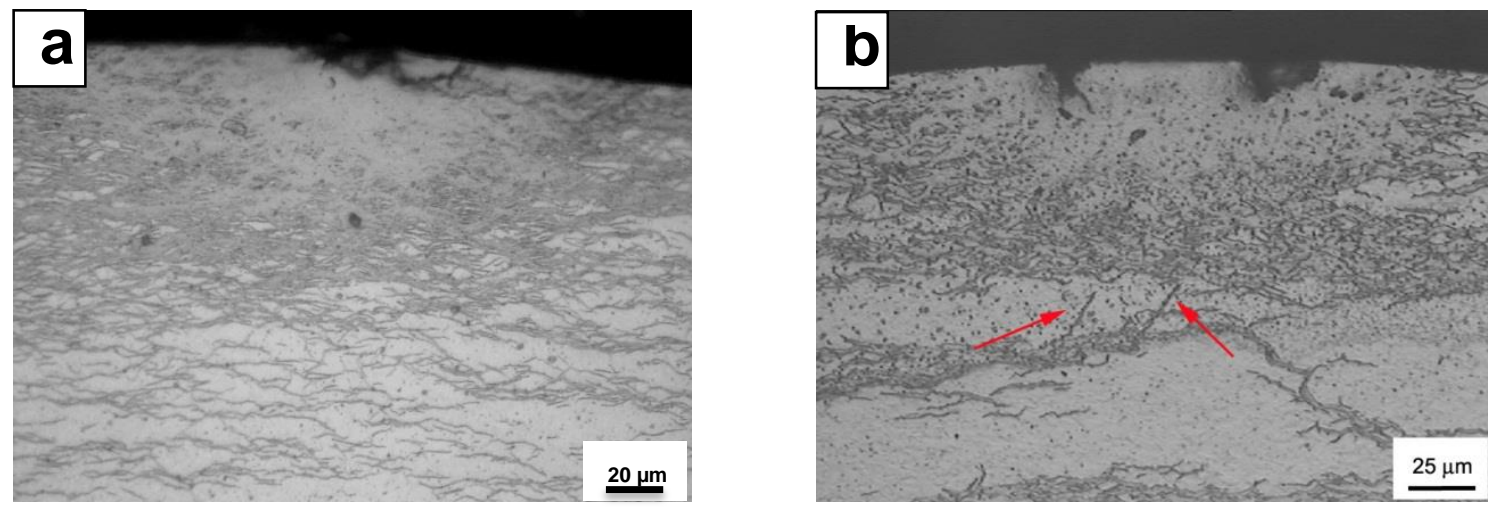

Figure 10: Section of blisters in specimens: a) 5.5-R and b) 5.5-R/HRT. Red arrows indicate radial hydrides.

Due to the small thickness of the claddings, if the cold contact is large the obtained blister crosses the whole thickness and the hydride reorientation cannot be analyzed. It was necessary to reduce the cold contact size in order to obtain smaller blisters with lower density of hydrides precipitated around them. Blisters with smaller size (depth of $0.07-0.08 \mathrm{~mm}$ ), were obtained in specimen 5.5-R and 5.5-R/HRT where isolated particles of refractory powders were interposed between the concave cold finger and the sample. Particles in 
alumina and aluminum powders have a lower size and they stick together during blister formation process giving rise to deeper blisters. Specimen 5.5-R was sectioned without HRT (section A-A in Figure 2). A few radial hydrides of $\sim 10 \mu \mathrm{m}$ were observed (Figure 10.a). However, in the blister of specimen 5.5-R/HRT submitted to HRT, radial hydrides with more than $25 \mu \mathrm{m}$ in length were observed, as indicated in Figure 10.b by arrows, which would indicate that radial hydrides effectively increased with the internal pressure of the tube. This test put in evidence that, in spite of the small size of the blister, the stresses around it are - added to the $81 \mathrm{MPa}$ produced by inner pressure - enough to overcome the threshold for radial precipitation.

Further HRT with longer time must be made to verify if DHC may produce cladding perforation under dry storage conditions.

\section{CONCLUSIONS}

In the present work different experimental techniques were applied in order to reproduce defects of feasible occurrence in fuel cladding. Sections of Zry-4 clads containing these defects were subjected to thermal treatment under inner pressure (HRT) to verify if radial hydrides precipitate and grow.

The obtained experimental results can be summarized as follows:

- Nor continuous (rim) neither discontinuous (spots) hydrides layers produced hydride reorientation during HRT.

- The best condition to obtain small blisters to investigate the possibility of hydrides reorientations were obtained using a concave cold finger with refractory powders as contact during 4 days at $320-360^{\circ} \mathrm{C}$.

- Radial hydrides with more than $25 \mu \mathrm{m}$ length were observed after submitting the tube with blister to the HRT during a month.

- It was demonstrated that, in Zry-4 claddings, the stresses around the blister are enough to produce radial hydrides. Besides, during HRT these stresses, added to the hoop stress produced by inner pressure, are enough to increase radial hydride length.

\section{ACKNOWLEDGMENTS}

This research was partially supported by the IAEA under the research contract AE 17339 .

\section{BIBLIOGRAPHY}

[1] CHAO, C.K., YANG, K.C., TSENG, C.C., "Rupture of spent fuel Zircaloy cladding in dry storage due to delayed hydride cracking", Nuclear Engineering and Design, v. 238, n. 1, pp. 124-129, Jan. 2008.

[2] MCMINN, A., DARBY, E.C., SCHOFIELD, J.S., "The thermal solid solubility of hydrogen in Zirconium alloys", In: Zirconiumin the Nuclear Industry: Twelfth International Symposium, STP 1354, ASTM Publication, pp. 173-193, 1998.

[3] BAI, J.B., PRIOUL, C., FRANCOIS, D., "Hydride embrittlement in Zircaloy-4 plate: Part I. Influence of microstructure on the hydride embrittlement in Zircaloy- 4 at $20^{\circ} \mathrm{C}$ and $350{ }^{\circ} \mathrm{C}$ ", Metallurgical and Materials Transactions A, v. 25, n. 6, pp. 1185-1197, Jun. 1994

[4] YUNCHANG, F., KOSS, D.A., "The influence of multiaxial states of stress on the hydrogen embrittlement of Zirconium alloy sheet", Metallurgical Transactions A, v. 16, n. 4, pp. 675-681, Apr. 1985.

[5] LIN, S.C., HAMASAKI, M., CHUANG, Y.D., "The effect of dispersion and spheroidization treatment of $\Delta$ Zirconium hydrides on the mechanical properties of Zircaloy", Nuclear Science and Engineering, v. 71, $\mathrm{n}$. 3, pp. 251-266, Sep. 1979.

[6] DOMIZZI, G., Influencia del hidrógeno sobre las aleaciones base circonio”, $\mathrm{PhD}$, Instituto de Tecnología "Prof. Jorge A. Sabato", Buenos Aires, Argentina, 2000.

[7] DOMIZZI, G., VIGNA, G., BERMÚDEZ S., OVEJERO-GARCÍA, J., "Hydride distribution around a blíster in Zr-2.5Nb pressure tubes, Journal of Nuclear Materials, v.275, n. 3 , pp. 255-267, Nov. 1999.

[8] MARSHALL, R.P., LOUTHAN, M.R., "Tensile properties of Zircaloy with oriented hydrides", Trans $A S M$, v. 56, n. 12 , pp. 693-700, Dec. 1963

[9] VALANCE, S., BERTSCH, J., ALAM, A.M., "Statistical analysis of hydride reorientation properties in irradiated Zircaloy-2", In: Zirconium in the Nuclear Industry: 16th International Symposium, STP 1529,

ASTM Publication, pp. 523-542, 2012 
[10] AOMI, M., BABA, T., MIYASHITA, T., KAMIMURA, K., et al., "Evaluation of hydride reorientation behavior and mechanical properties for high-burnup fuel-cladding tubes in interin dry storage", In: Zirconiumin the Nuclear Industry: 15th International Symposium, STP 1505, ASTM Publication, pp. 651$671,1998$.

[11] GLENDENING, A., KOSS, D.A., MOTTA, A.T., et al., “ Failure of hydrided Zircaloy-4 under equalbiaxial and plane-strain tensile deformation”, In: Zirconiumin the Nuclear Industry: Fourteenth International Symposium, STP 1467, ASTM Publication, pp. 833-848, 2004.

[12] ELLS, C.E., "Influence of Hydrogen on the behavior of Zirconium alloys in CANDU reactor", The Metallurgical Society of Canadian Institut of Metals, Annual Volume, pp. 32-44, 1978.

[13] HERMANN, A., YAGNIK, S.K., GAVILLET. D., "Effect of local hydride accumulation on Zircaloy cladding mechanical properties" ", In: Zirconiumin the Nuclear Industry: 15th International Symposium, STP 1505, ASTM Publication, pp. 141-162, 2009. 